\title{
REDUCTION OF ANTERIOR UVEITIS FLARES IN PATIENTS WITH AXIAL SPONDYLOARTHRITIS DURING CERTOLIZUMAB PEGOL TREATMENT: 96-WEEK RESULTS FROM THE C-VIEW STUDY
}

Irene van der Horst-Bruinsma ${ }^{1}$, Rianne Elise van Bentum ${ }^{1}$, Frank D. Verbraak ${ }^{1}$, Thomas Rath ${ }^{2}$, Bengt Hoepken ${ }^{3}$, Oscar Irvin-Sellers ${ }^{4}$, Thomas Kumke $^{3}$, Lars Bauer ${ }^{3}$, Rodrigo Luppino-Assad ${ }^{5, \star}$, Martin Rudwaleit ${ }^{6}$

1.Amsterdam University Medical Center, Amsterdam, The Netherlands. 2.St Franziskus-Hospital, Münster, Germany. 3.UCB Pharma, Monheim am Rhein, Germany. 4.UCB Pharma, Slough, UK. 5.Universidade de São Paulo, São Paulo (SP), Brazil. 6.Klinikum Bielefeld, Berlin, Germany.

*Corresponding author: rodluppinoassad@gmail.com

\section{BACKGROUND}

Acute anterior uveitis (AAU) is the most common extra-articular manifestation in axial spondyloarthritis (axSpA), affecting up to $40 \%$ of patients1. Tumor necrosis factor inhibitors were shown to reduce the incidence of AAU flares in patients with radiographic axSpA (ankylosing spondylitis)2-4; however, few studies have focused on patients across the full axSpA spectrum. We report 2-year outcomes from the phase 4, open-label CVIEW study (NCT03020992), which investigated the impact of certolizumab pegol (CZP) treatment on AAU in patients with active axSpA and a recent history of AAU.

\section{MATERIALS AND METHODS}

C-VIEW prospectively investigated patients with active axSpA who were HLA-B27 positive and had recurrent AAU, with a history of $\geq 1 \mathrm{AAU}$ flare in the year prior to baseline (complete study design are described elsewhere5). The primary efficacy variable was the incidence of AAU flares during 96 weeks of CZP treatment versus the 2-year pre-baseline period. Acute anterior uveitis incidence was evaluated using Poisson regression adjusted for duration of time in each period, with period (pre- and postbaseline) and axSpA disease duration as covariates. Secondary efficacy variables were ASAS20/40 response rates, and mean ASDAS and mean BASDAl to week 96.

a) AAU incidence rate (Poisson-adjusted)

b) Proportion of patients experiencing 0,1 or $\geq 2$ AAU flares
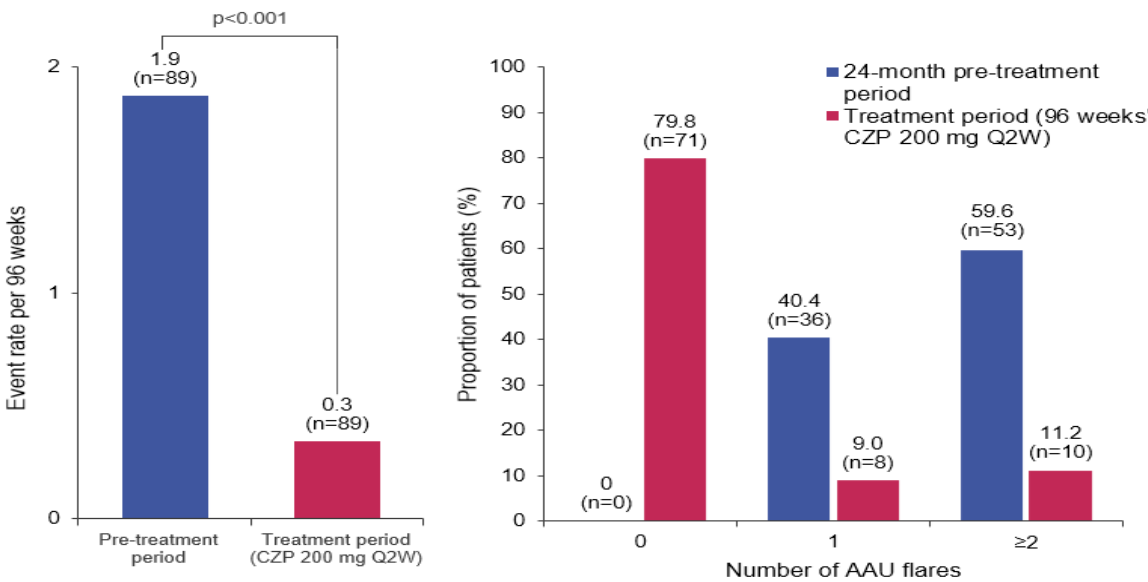

Treatment period: after start of study medication until week 96 or discontinuation visit. Pretreatment period: 24 months prior to treatment start. Flares of the same eye are combined and counted as one flare if the time interval between two subsequent flares is $<3$ months (90 days). Patients received CZP $400 \mathrm{mg}$ at weeks 0/2/4, then $200 \mathrm{mg}$ Q2W through 96 weeks. a) Poisson regression analysis, with period (pre-/postbaseline) and axSpA disease duration as covariates and adjusting for the length of time in the pre- and postbaseline periods. AAU: acute anterior uveitis; CZP: certolizumab pegol; Q2W: every 2 weeks.

Figure 1. Summary of AAU flares (observed data). 

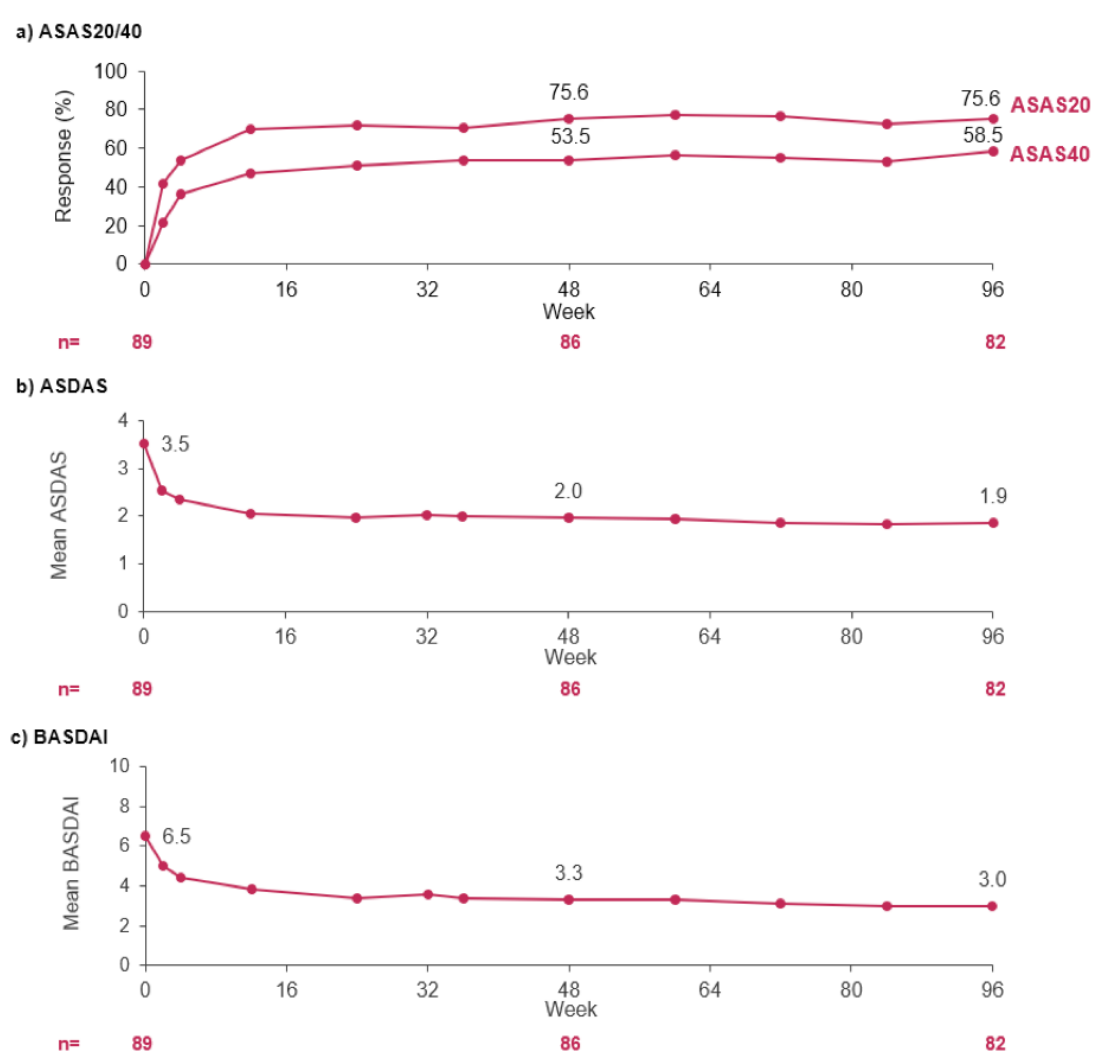

Patients received CZP 400 mg at weeks 0/2/4, then 200 mg Q2W through 96 weeks. ASAS20/40: Assessment of SpondyloArthritis International Society 20\%/40\% response; ASDAS: Ankylosing Spondylitis Disease Activity Score; BASDAl: Bath Ankylosing Spondylitis Disease Activity Index; CZP: certolizumab pegol; Q2W: every 2 weeks.

Figure 2. Changes in axSpA disease activity to week 96 (observed data).

\section{RESULTS}

Eighty-nine of 115 patients initiated CZP treatment; $83 / 115$ completed week 96 . The primary analysis revealed an $82 \%$ reduction in the incidence of AAU flares during CZP treatment compared with pre-baseline (Fig. 1; rate ratio [95\% Cl]: 0.18 [0.12, 0.28], $p<$ 0.001). The percentage of patients experiencing $\geq 1$ and $\geq 2$ AAU flares reduced from $100 \%$ and $59.6 \%$ prebaseline to $20.2 \%$ and $11.2 \%$ during treatment. There were also improvements in axSpA disease activity (Fig. 2): by week 96, 75.6\% and 58.5\% of patients had achieved ASAS20 and ASAS40 responses, respectively. ASDAS and BASDAI also improved substantially over the 96-week treatment period. No new safety signal was identified, compared to previous reports5.

\section{CONCLUSION}

These data support the use of CZP for the treatment of patients with axSpA and a history of recurrent AAU. During 96-week CZP treatment, there was a significant reduction of $82 \%$ in the AAU flare rate compared to pre-baseline. There were also substantial improvements in patients' axSpA disease activity.

\section{ACKNOWLEDEGMENTS}

Editorial services were provided by Costello Medical. 


\section{FUNDING}

This study was funded by UCB Pharma.

\section{REFERENCES}

1. Martin TM, Smith JR, Rosenbaum JT. Anterior uveitis: current concepts of pathogenesis and interactions with the spondyloarthropathies. Curr Opin Rheumatol. 2002;14(4):337-41. https://doi.org/10.1097/00002281-200207000-00001

2. Van der Heijde D, Dougados M, Landewé R, Sieper J, Maksymowych WP, Rudwaleit M, Van den Bosch F, et al. Sustained efficacy, safety and patient-reported outcomes of certolizumab pegol in axial spondyloarthritis: 4-year outcomes from RAPID-axSpA. Rheumatology (Oxford). 2017;56(9):1498-509. https://doi.org/10.1093/rheumatology/kex174

3. Van Bentum RE, Heslinga SC, Nurmohamed MT, Gerards AH, Griep EN, Koehorst CBJM, Kok MR et al. Reduced occurrence rate of acute anterior uveitis in ankylosing spondylitis treated with golimumab —-The GO-EASY Study. J Rheumatol. 2019;46:153-9. http:// doi.org/10.3899/jrheum.180312

4. Van Denderen JC, Visman IM, Nurmohamed MT, Suttorp-Schulten MS, van der Horst-Bruinsma IE. Adalimumab significantly reduces the recurrence rate of anterior uveitis in patients with ankylosing spondylitis. J Rheumatol. 2014;41(9):1843-8. https://doi. org/10.3899/jrheum.131289

5. Van der Horst-Bruinsma I, van Bentum R, Verbraak FD, Rath T, Rosenbaum JT, Misterska-Skora M, Hoepken B, et al. The impact of certolizumab pegol treatment on the incidence of anterior uveitis flares in patients with axial spondyloarthritis: 48-week interim results from C-VIEW. RMD Open. 2020;6(1):e001161. https://doi.org/10.1136/rmdopen-2019-001161 